Çukurova Üniversitesi Mühendislik Mimarlık Fakültesi Dergisi, 32(4), ss. 79-86, Aralık 2017

Çukurova University Journal of the Faculty of Engineering and Architecture, 32(4), pp. 79-86, December 2017

\title{
Farklı İklim Bölgelerindeki Seralar için Isı Gereksinimlerinin Modellenmesi
}

\author{
Zeynep ZAIMOĞLU ${ }^{* 1}$ \\ ${ }^{I}$ Çukurova Üniversitesi, Mühendislik ve Mimarlık Fakültesi, Çevre Mühendisliği Bölümü, \\ Adana
}

Geliş tarihi: 07.06.2017

Kabul tarihi: 19.12.2017

$\ddot{\mathbf{O} z}$

Seralardan kaliteli yüksek verimin alınabilmesi için seraların ısıtılması gereklidir. Ancak 1sıtma giderleri üretim maliyetini ciddi anlamda etkilemektedir. Seralarda sürdürülebilirlik, enerji verimliliğini artırmakla sağlanabilir. Enerji verimliliğinin artırılması fosil enerji kaynakları yerine atık üretmeyen yenilenebilir enerji kaynaklarının kullanılması ile mümkün olabilmektedir.

Türkiye'de seracılık iklimin sağladığı avantajlar nedeniyle yaygın olarak Akdeniz sahil şeridinde yapılmaktadır. Ancak son yıllarda jeotermal kaynakların bulunduğu alanlarda seracılık önem kazanmaya başlamış ve bu yerlerde kurulan modern seralardan kaliteli yüksek verim alınmaya başlanmıştır.

Yapılan bu çalışmada Türkiye'de sera 1sıtmasında kullanılan kömür ile jeotermal enerji kaynaklarının maliyeti ve kömürün atmosfere olan $\mathrm{CO}_{2}$ salınımı karşılaştııılmıştır. Elde edilen sonuçlara göre jeotermal enerjinin birim fiyatı 0,06 $/ \mathrm{kWh}$ olduğunda, jeotermal kaynaklara sahip Aydın ilinde yapılacak seracılık büyük avantajlara sahip olurken, Kütahya'da serada yapılacak domates üretimi Antalya ile ancak rekabet edebilecektir. Ancak sera 1sıtmasında çevreye zarar vermeden jeotermal kaynakların kullanılması durumunda $\mathrm{CO}_{2}$ salınımı açısından jeotermal bölgelerin Akdeniz bölgesindeki seracılığa göre büyük avantajları olacaktır.

Anahtar kelime: Jeotermal enerji, Tarımsal seralar, Seralarda 1sıtma

\section{Modeling of Heat Requirements for Agricultural Greenhouse in Different Climate Regions}

\begin{abstract}
It is necessary to heat the greenhouses in order to obtain a high quality yield from the surroundings. However, heating costs seriously affect the cost of production. Sustainability can be achieved by improving energy efficiency. Increasing energy efficiency is possible by using renewable energy sources that do not produce waste instead of fossil energy sources.
\end{abstract}

"Sorumlu yazar (Corresponding author): Zeynep ZAİMOĞLU, zeynepz@cu.edu.tr 
Due to the advantages of greenhouse climate in Turkey, it is widely used on the Mediterranean coast. However, in recent years, greenhouses have gained importance in areas where geothermal resources are present and high quality yields have been started to be obtained from modern greenhouses established in these places.

In this study, the cost of coal and geothermal energy sources used in greenhouse heating in Turkey and the $\mathrm{CO}_{2}$ emissions of the cargo atmosfere are compared. According to the results obtained, when the unit price of the geothermal energy is $0.06 \mathrm{E} / \mathrm{kWh}$, the greenhouse production in Aydin province with geothermal resources will have great advantages, while the production of tomatoes to be made in Kütahya can only compete with Antalya. However, in case of using geothermal resources without harming the environment in the greenhouse heating, geothermal regions will have great advantages in terms of $\mathrm{CO}_{2}$ emission compared to greenhouse in the Mediterranean region.

Keywords: Geothermal energy, Agricultural greenhouses, Heating of greenhouses

\section{GİRIŞ}

Türkiye'de seracılık 1940 yıllarında ilk defa Akdeniz bölgesinde özellikle Antalya'da başlamış, buradan ekolojik koşullara bağımlı bir gelişme göstererek Ege ve Marmara bölgelerine yayılmıştır. Günümüzde örtü altı yetiştiriciliği en yoğun olarak Akdeniz bölgesinde yapılmaktadır. $\mathrm{Bu}$ bölge toplam örtü altı varlığımızın \%84'üne sahiptir. Akdeniz bölgesinden sonra \%9,4'lük pay ile Ege bölgesi, \%4,8 ile Karadeniz ve \%1,7 ile Marmara bölgeleri gelmektedir. Akdeniz Bölgesinde bulunan Antalya ilimiz toplam 22000 hektar ile ülkemiz toplam örtü altı varlığının $\% 37$ 'sine sahiptir.

Seracılıktaki yeni gelişmeler bu sektörde sürdürülebilirliği sağlamaya yönelik gayretler ile paralel olarak ortaya çıkmaktadır. Seraların yapısal özelliklerinin iyileştirilmesi, iklimlendirme ve alternatif enerji kaynaklarından faydalanma, kontrollü koșullarda üretim, topraksız tarımın yaygınlaştırılması, entegre hastalık ve zararlı yönetimi, sertifikalı güvenli ve izlenebilir gıda üretimi şeklinde özetlenebilir. $\mathrm{Bu}$ nedenle son yıllarda çevre kontrollü tarımsal üretim teknikleri giderek artan bir ivme ile gelişme göstermektedir. Çevre kontrollü bitkisel üretim sistemlerinde doğal çevresel etmenler bütün yönleri ile bitkilerin optimum istekleri doğrultusunda değiştirilmeye çalışılmaktadır. Bitkisel üretimde çevre kontrollü üretimin en yaygın ve etkin uygulaması seralarda gerçekleştirilmektedir.
Seralarda 1sitma üretim maliyetini ciddi anlamda etkilemektedir. Isıtma giderleri bölge iklimine bağlı olarak, toplam işletme masraflarının \%30-80’i arasında değişim göstermektedir. Akdeniz iklim koşullarında 1sı perdeli PE plastik seralarda sicaklığın gece saatlerinde $16^{\circ} \mathrm{C}$ 'de tutulmak istenmesi durumunda gereksinilen yakıt (İthal kömür) $16 \mathrm{~kg} / \mathrm{m}^{2}$ olmaktadır. Bu da üretim maliyetleri içinde yaklaşık \%22'lik bir orana sahip olmaktadır [1].

Akdeniz bölgesinde bulunan Adana ve Antakya ili için yakıt tüketimlerini saatlik iklim değerlerinden giderek hesaplamışlardır. Her iki araştırıcı da Akdeniz iklimine sahip bu illerimizde serada sicaklığın gece/gündüz $16^{\circ} \mathrm{C}$ 'de tutulması durumunda, yaklaşı $10 \mathrm{l} / \mathrm{m}^{2}$ yakıt (Fuel-Oil) tüketimi belirlemişlerdir [2,3].

Akdeniz iklim koşullarında 1sıtılmayan seralardan alınan domates verimi $7-14 \quad \mathrm{~kg} / \mathrm{m}^{2}$ arasında değişirken [4], düzenli olarak isıtılan seralardan alınan verim $28-34 \mathrm{~kg} / \mathrm{m}^{2}$,ye kadar yükselmektedir [1].

Türkiye'de son yıllarda kurulan modern seralarda düzenli 1sıtma yapılmakta ve yakıt olarak ithal kömür kullanılmaktadır. Sera 1sıtmasında kullanılan fosil enerji kaynaklarının en büyük sakıncası atmosfere verdikleri $\mathrm{CO}_{2}$ emisyonudur. Seralarda sürdürülebilirlik, enerji verimliliğini artırmakla sağlanabilir. Enerji verimliliğinin artırılması fosil enerji kaynakları yerine atık 
üretmeyen yenilenebilir enerji kaynaklarının kullanılması ile mümkün olabilmektedir.

Türkiye'de jeotermal kaynaklar, Akdeniz ikliminin hakim olduğu bölgelerde (Aydın) ve karasal iklimin hakim olduğu iç bölgelerde (Kütahya) bulunmaktadır. Akdeniz ikliminin hakim olduğu yerlerde üretim periyodu on ay sürerken, iç bölgelerde bu süre oniki aya kadar çıkabilmektedir. Bu durum birim alandan alınacak ürün miktarını etkilemektedir. Tüm yıl üretimin yapılabildiği bölgelerde üretim periyodunun uzunluğuna bağlı olarak birim sera alanından 50 $\mathrm{kg}$ domates verimi alınırken, üretim periyodunun daha k1sa olduğu yerlerde kurulan modern seralardan elde edilen ürün miktarı $32 \mathrm{~kg} / \mathrm{m}^{2}$ olmaktadır. Ancak hava sıcaklığının daha düşük olduğu karasal iklim bölgelerinde tüketilen 1s1 enerjisi, Akdeniz bölgesinde tüketilen 1S1 enerjisinin yaklaşık 3-4 katı olmaktadır [1].

Türkiye jeotermal 1S1 potansiyeli bakımından Dünyanın 7. Avrupa'nın ise 1. jeotermal kaynağa sahip ülkesi durumundadır. Ancak kullanım düzeyi kaynakların yaklaşık \%3'ü seviyesinde olup ülke kapasitesine oranla oldukça düşüktür. Türkiye'de enerji ihtiyacı da dikkate alındığında jeotermal kaynakların kullanımının artırılması ülke ekonomisi açısından oldukça önemlidir. Türkiye'de örtü altı varlığımız ve jeotermal enerji ile 1sıtılan sera alanlarımızın büyüklüğü yaklaşık 280 ha olup Türkiye'deki sera varlığımızın yaklaşık \%1'i civarındadır. Tarım Bakanlığının 2012 yılından itibaren hayata geçirdiği "Alternatif Üretim Yöntemlerinin Geliştirilmesi Projesi" kapsamında, jeotermal kaynakların bulunduğu illerimizde modern seracılığın yaygınlaştırılması, mevcut durumun analiz edilmesi ve sera fizibilitelerinin hazırlanması amaçlanmaktadır [5].

Yapılan bu çalışmada, jeotermal kaynaklar bakımından oldukça zengin potansiyele sahip Kütahya ve Aydın illerimizde kurulacak farklı donanımlara sahip seralarda üretim periyodu boyunca ortaya çıkacak $1 \mathrm{~s} 1$ enerjisi gereksinimlerinin belirlenmesi ve yapılacak olan domates üretiminde jeotermal ve fosil enerji kaynaklarının enerji maliyeti karşılaştırılarak jeotermal enerjinin rekabet edebilirlik amacıyla fiyat belirlemesi amaçlanmıştır.

\section{MATERYAL VE METOT}

Yapılan çalışmada seralarda 1sı enerjisi gereksiniminin belirlenmesinde, geliștirilen ISIGER-SERA uzman sistemi kullanılmıştır [1]. Hesaplamalarda son yıllarda kurulan modern sera boyutları esas alınmıştır (Çizelge 1). Seralarda kullanılan tek kat UV katkılı PE plastik örtünün

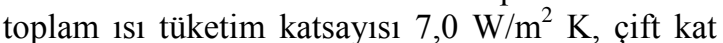
$\mathrm{PE}$ plastik örtünün ise $5,1 \mathrm{~W} / \mathrm{m}^{2} \quad \mathrm{~K}$ olarak alınmıştır $[6,7]$.

Çizelge 1. Hesaplamalarda esas alınan sera boyutlar1.

\begin{tabular}{|l|c|c|l|c|c|}
\hline Boyut & Birim & Boyut & Birim & \\
\hline $\begin{array}{l}\text { Bölme } \\
\text { genişliği }\end{array}$ & $\mathrm{m}$ & 9,6 & $\begin{array}{l}\text { Mahya } \\
\text { yüksekliği }\end{array}$ & $\mathrm{m}$ & 7,0 \\
\hline $\begin{array}{l}\text { Bölme } \\
\text { sayısı }\end{array}$ & Adet & 10 & $\begin{array}{l}\text { Taban } \\
\text { alanı }\end{array}$ & $\mathrm{m}^{2}$ & 4800 \\
\hline $\begin{array}{l}\text { Sera } \\
\text { uzunluğu }\end{array}$ & $\mathrm{m}$ & 50 & Örtü Alanı & $\mathrm{m}^{2}$ & 7338 \\
\hline $\begin{array}{l}\text { Yan duvar } \\
\text { yüksekliği }\end{array}$ & $\mathrm{m}$ & 4,25 & $\mathrm{~A}_{\mathrm{H}} / \mathrm{A}_{\mathrm{G}}$ & - & 1,53 \\
\hline
\end{tabular}

ISIGER-SERA uzman sistemle belirlenen yıllık 1s1 enerjisi gereksiniminden gidilerek yakıt tüketimi 1 nolu eşitlik yardımıyla hesaplanmıştır. Hesaplamalarda ithal kömürün alt isıl değeri $8,14 \mathrm{kWh} / \mathrm{kg}$, ortalama işletme verimi $\% 65$ olarak alınmıştır (http://www.tesisat. com.tr/yayin/yakitfiyatlari/). Sera 1sitmasında kullanılan kömürün atmosfere olan $\mathrm{CO}_{2}$ salınımları 2 nolu eşitlik yardımı ile hesaplanmıştır.

$B_{y}=\frac{q_{H}}{H_{u} \eta_{g e s}}$

$\mathrm{SEGM}_{\mathrm{y}}=\mathrm{B}_{\mathrm{y}} * \mathrm{Hu} * \mathrm{FSEG}$

Eşitliklerde;

$\mathrm{B}_{\mathrm{y}}=$ Birim alana tekabül eden yakıt miktarı $\left(\mathrm{kg} \mathrm{m}^{-2}\right.$ veya $\mathrm{m}^{3} \mathrm{~m}^{-2}$ ),

$\mathrm{q}_{\mathrm{H}}=$ Seranın 1sı enerjisi gereksinimi $\left(\mathrm{kWh} \mathrm{m}^{-2}\right)$, 
$\eta_{\text {ges }}=$ Randiman

$\mathrm{SEGM}_{\mathrm{y}}$ : Y1llık $\mathrm{CO}_{2}$ emisyon miktarı (kg eşd. $\left.\mathrm{CO}_{2}\right)$ FSEG : Yakıt cinsine göre $\mathrm{CO}_{2}$ emisyonu dönüşüm katsayısı $\left(\mathrm{kg}\right.$ eşd. $\left.\mathrm{CO}_{2} / \mathrm{kWh}\right)$. İthal kömür için bu değer $0,421 \mathrm{~kg} / \mathrm{kWh}$ alınmıștır [8].

\section{BULGULAR VE TARTIŞMA}

Türkiye'de seracılığın yoğun olarak yapıldığı Antalya ilinin ve jeotermal kaynaklar bakımından zengin olan Aydın ve Kütahya illerinin uzun yıllık ortalama sıcaklık ve günlük toplam radyasyon değerleri incelendiğinde, bu illerimizde yılın belli aylarında sıcaklık değerlerinin $12^{\circ} \mathrm{C}$ 'nin altına düştüğü görülmektedir. Bu koșullarda seralardan kaliteli yüksek verimin elde edilebilmesi için 1sitma yapilmalidir $[9,10]$.
Jeotermal kaynaklar bakından zengin Aydın illimiz Akdeniz iklim özelliği gösterirken, Kütahya ilinin iklim değerleri tipik karasal iklimi temsil etmektedir. Kütahya ilinin uzun yıllık iklim değerleri incelendiğinde, Ekim-Nisan döneminde sıcaklık değerlerinin $0^{\circ} \mathrm{C}-12^{\circ} \mathrm{C}$ arasında değiştiği görülmektedir. Aydın ilinde ise sadece Aralık-Mart döneminde serada isitma ihtiyacı ortaya çıkmaktadır. Ancak Kütahya ilinde, yıl boyunca aylık ortalama sıcaklık değerleri $22^{\circ} \mathrm{C}$ 'nin üstüne çıkmadığından, bu ilimizde 1sıtma yapılması durumunda yilın 12 ayında serada üretim yapılabilecektir. Aydın ilinde ise Akdeniz sahil şeridinde olduğu gibi, Haziran ayından sonra dış sıcaklık değerleri $22^{\circ} \mathrm{C}$ 'nin üstüne çıktığı için, seralarda soğutma önlemi almadan bitkisel üretimin devamı mümkün olmayacaktır (Çizelge 2).

Çizelge 2. Aydın ve Kütahya illerinin uzun yıllık aylık ortalama sıcaklık değerleri ve bu değerlere bağlı serada alınması gerekli olan iklimlendirme önlemleri

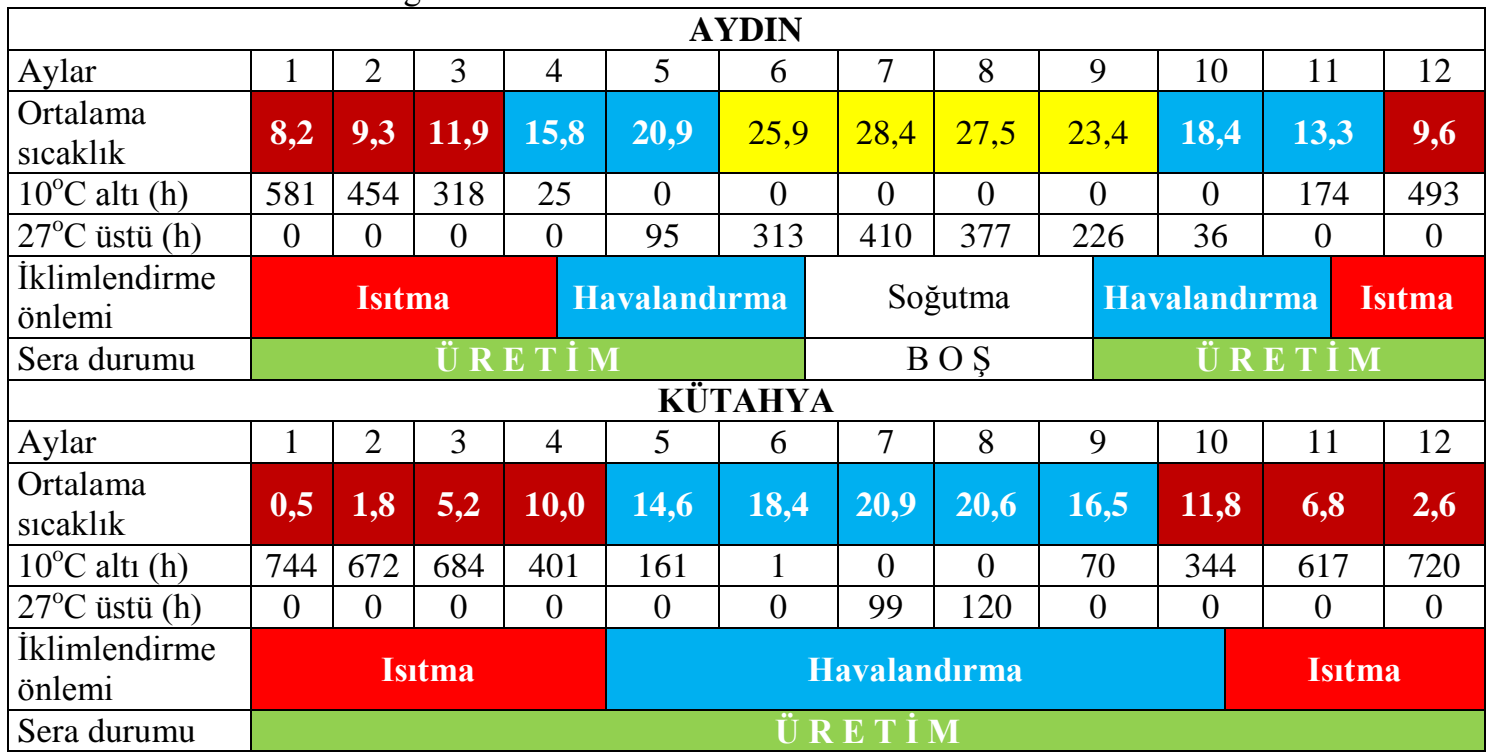

Çizelge 2'de Kütahya ve Aydın illeri için uzun yıllık saatlik iklim değerlerinden elde edilen sıcaklık yinelenmeleri verilmiştir. Çizelgeden de görüleceği gibi Kütahya'da Aralık, Ocak ve Şubat aylarında günün 24 saatinde sicaklık değerleri $10^{\circ} \mathrm{C}$ 'nin altında seyrettiğinden bütün gün serada 1sıtma ihtiyacı ortaya çıkmaktadır. Mart ayından sonra, gündüz saatlerinde 1sitma ihtiyacı ortadan kalkmaktadır. Kütahya'da Temmuz ve Ağustos aylarında sicaklık değerleri sadece 219 saat $27^{\circ} \mathrm{C}$ 'nin üstünde seyretmektedir. Ancak bu aylarda sıcaklık $30^{\circ} \mathrm{C}$ 'nin üzerine çıkmadığından, serada yapılacak gölgeleme ile bitkisel üretimin devamı sağlanabilecektir. Aydın'da Ocak ayının 744 saatinin 581 saatinde serada 1sitma yapma gereği ortaya çıkarken, bu değer nisan ayında 25 
saate kadar düşmektedir. Diğer bir ifade ile Aydın ilinde Nisan ayında serada 1sıtma gereği ortadan kalkmaktadır. Ancak Aydın ilinde saatlik sıcaklık tekerrürleri incelendiğinde, Haziran, Temmuz ve Ağustos aylarında sıcaklık değerleri günün belli saatlerinde $30^{\circ} \mathrm{C}$ 'nin üstüne çıkmaktadır. Belirtilen nedenle Aydın ve Antalya'da Haziran ayının sonlarına doğru seralar boş bırakılmaktadır.

\subsection{Isıtma Sistemleri İçin Gereksinilen Isı Gücü Değerlerinin Karşılaştırılması}

Kütahya, Aydın ve Antalya illeri için yılın saatlerine bağlı hesaplanan ısı gücü gereksinimleri şekil 1'de verilmiştir. Şekilden de görüleceği gibi serada sicaklığın gece/gündüz $16 / 18^{\circ} \mathrm{C}$ 'de tutulmak istenmesi durumunda en yüksek 1s1 gücü gereksinimi, Kütahya'da $\left(190 \mathrm{~W} / \mathrm{m}^{2}\right)$ ortaya çıkarken, bunu Aydın $\left(120 \mathrm{~W} / \mathrm{m}^{2}\right)$ ve Antalya $\left(100 \mathrm{~W} / \mathrm{m}^{2}\right)$ takip etmektedir.

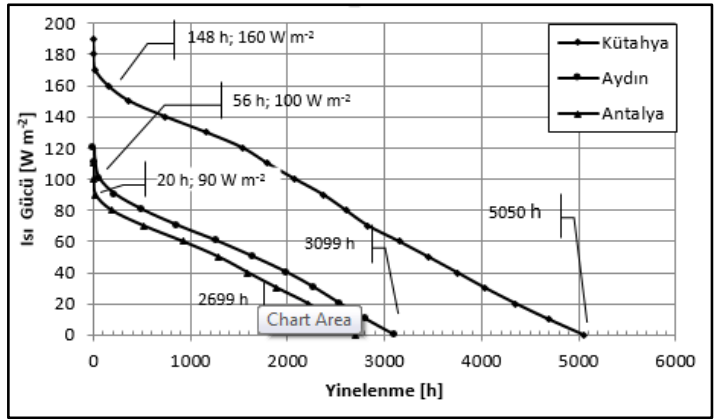

Şekil 1. Kütahya, Aydın ve Antalya illeri iklim koşullarında tek katlı PE plastik ile örtülmüş serada sicaklığın gündüz/gece $18 / 16^{\circ} \mathrm{C}$ 'de tutulması durumunda, y1l içinde ortaya çıkan 1sı gücü tekerrürleri (Havalandırma sıcaklığ $125^{\circ} \mathrm{C}$, Isıtma borular1 yere yakın)

Serada 1S1 gücünün belirlenmesi kadar bu güce yılın kaç saatinde ihtiyaç duyulduğunun bilinmesi de önem arz etmektedir. Şekil 1'den de görüleceği gibi, Kütahya ilinde serada sıcaklığın gündüz/gece $18 / 16^{\circ} \mathrm{C}^{\prime} \mathrm{de}$ tutulabilmesi için gerekli olan maksimum 1sı gücü değeri $190 \mathrm{~W} / \mathrm{m}^{2}$ olurken, yılın 5050 saatinde 1 sitma ihtiyacı ortaya çıkmaktadır.
Aydın ilinde ise gereksinilen maksimum 1sı gücü $120 \mathrm{~W} / \mathrm{m}^{2}$ olarak hesaplanırken, y1lın 3099 saatinde isıtmaya ihtiyaç duyulmaktadır.

\subsection{Seralarda Isı Enerjisi Gereksiniminin Karşılaştırılması}

Antalya, Aydın ve Kütahya illerinde farklı donanımlara sahip PE plastik seralarda sıcaklığın gündüz/gece $18 / 16^{\circ} \mathrm{C}$ 'de tutulmak istenmesi durumunda üretim periyodu boyunca gereksinilen 1S1 enerjisi, 1sıtmada kullanılan kömür miktarı ve kömürün atmosfere verdiği $\mathrm{CO}_{2}$ emisyonları ISIGER-SERA uzman sistemle [1] hesaplanarak Çizelge 3'te verilmiştir. Çizelgeden de görüleceği gibi en yüksek 1sı enerjisi gereksinimi Kütahya ilinde tek kat PE plastik ile örtülmüş serada $\left(432,8 \mathrm{kWh} / \mathrm{m}^{2} \mathrm{y} 1 \mathrm{l}\right)$ ortaya çıkarken, bunu Aydın $\left(165,2 \mathrm{kWh} / \mathrm{m}^{2} \mathrm{y} 1 \mathrm{l}\right)$ ve Antalya $\left(130,4 \mathrm{kWh} / \mathrm{m}^{2} \mathrm{y} 1 \mathrm{l}\right)$ illerindeki isı enerjisi takip etmektedir.

Antalya, Aydın ve Kütahya iklim koşullarında farklı donanımlara sahip PE plastik seralarda sıcaklığın gece/gündüz $16 / 18^{\circ} \mathrm{C}$ 'de tutulması durumunda, birim sera alanı için gereksinilen kömür miktarları verilmiştir (Çizelge 3). Antalya koşullarında gereksinilen kömür miktarı tek kat PE plastikle örtülmüş $1 \mathrm{~s} 1$ perdesiz serada $24,6 \mathrm{~kg} / \mathrm{m}^{2}$ olurken, yan duvarların çift kat PE plastikle kaplanması ve iyi yalıtılmış 1sı perdesinin kullanılması durumunda bu değer $16,2 \mathrm{~kg} / \mathrm{m}^{2}$,ye düşmektedir. Aydın iklim koşullarında yan duvarı çift kat PE plastikle örtülmüş 1sı perdeli serada kömür gereksinimi $21,7 \mathrm{~kg} / \mathrm{m}^{2}$ olurken, Kütahya koşullarında bu değer $58,2 \quad \mathrm{~kg} / \mathrm{m}^{2}$,ye yükselmektedir (Çizelge 3).

Seralarda yakıt tüketimi ve maliyetinin karşılaştırılabilmesi için elde edilen ürün miktarının da değerlendirmelerde dikkate alınması daha sağlıklı sonuçlar için gereklidir. Kütahya koşullarında üretim periyodunun Aydın ve Antalya'ya göre daha uzun olması, verimin daha fazla olmasına olanak sağlamaktadır. Düzenli olarak isitilan seralardan üretim periyodunun uzunluğuna bağlı olarak Kütahya'da $50 \mathrm{~kg} / \mathrm{m}^{2}$, Aydın'da $34 \mathrm{~kg} / \mathrm{m}^{2}$ ve Antalya'da $32 \mathrm{~kg} / \mathrm{m}^{2}$ domates verimi alınabilmektedir. Yan duvarları 
çift kat PE plastikle kaplı 1sı perdeli sera 1sıtmasında kömür kullanıldığında, bir kg domates üretimi için 1sıtma maliyeti, Kütahya'da $0,85 £ / \mathrm{kg}$, Aydın'da 0,47 £/kg ve Antalya'da 0,37 £/kg olmaktadır. Yapılan hesaplamalardan görüleceği gibi, Kütahya ve Aydın'da kömür kullanılarak yapılacak düzenli isıtma ile elde edilecek ürün Antalya koşullarında yapılacak üretimle rekabet edemeyecektir.

Aydın ve Kütahya'da serada yapılacak domates üretiminde 1sitmada kullanılacak jeotermal 1s1 enerjisinin birim fiyatı rekabet edebilirlik açısından büyük bir öneme sahiptir. DPT 9 .
Kalkınma Planı Jeotermal Çalışma Grubunun Raporuna göre, Jeotermal ile isınma bedeli $\mathrm{kWh}$ başına 1-2 cent (\$) olarak verilmektedir. Şekil 2'de farklı donanımlara sahip seralarda bir $\mathrm{kg}$ domates üretiminde gereksinilen 1sıtma giderlerine bağl1 olarak jeotermal isı enerjisi fiyatları verilmiştir. Şekilden de görüleceği gibi yan duvarları yalıtılmış 1S1 perdeli serada birim domates üretimi için harcanan 1sı enerjisi bedelinin $0,37 \quad € / \mathrm{kg}$ olabilmesi için jeotermal 1sı enerjisi kWh'nin 0,057 €’dan pazarlanması gereklidir. Serada 1s1 yalıtımının iyi olmaması durumunda bu fiyat 0,063 €/kWh’a kadar yükselmektedir.

Çizelge 3. Kütahya, Antalya ve Aydın illeri iklim koşullarında serada domates üretiminde gerekli olan 1sı enerjisi, kömür miktarı ve $\mathrm{CO}_{2}$ emisyon değerleri

\begin{tabular}{|c|c|c|c|c|c|c|c|c|c|c|c|c|}
\hline íl & \multicolumn{4}{|c|}{ Kütahya } & \multicolumn{4}{|c|}{ Aydın } & \multicolumn{4}{|c|}{ Antalya } \\
\hline Çatı örtüsü & \multicolumn{12}{|c|}{ Tek katlı PE plastik } \\
\hline $\begin{array}{l}\text { Yan duvar } \\
\text { örtüsü }\end{array}$ & $\begin{array}{l}\text { Tek } \\
\text { kat }\end{array}$ & \multicolumn{3}{|c|}{ Çift kat } & $\begin{array}{l}\text { Tek } \\
\text { kat }\end{array}$ & \multicolumn{3}{|c|}{ Çift kat } & $\begin{array}{l}\text { Tek } \\
\text { kat }\end{array}$ & \multicolumn{3}{|c|}{ Çift kat } \\
\hline $\begin{array}{l}\text { Gündüz/Gece } \\
\left({ }^{\circ} \mathrm{C}\right)\end{array}$ & \multicolumn{12}{|c|}{$18 / 16$} \\
\hline $\begin{array}{l}\text { IsI } \\
\text { perdesi/Yalıtım }\end{array}$ & Yok & Yok & Orta & İyi & Yok & Yok & Orta & İyi & Yok & Yok & Orta & İyi \\
\hline $\begin{array}{l}\text { Havalandirma } \\
\text { sicak }\left({ }^{\circ} \mathrm{C}\right)\end{array}$ & \multicolumn{12}{|c|}{25} \\
\hline Isitma sistemi & \multicolumn{12}{|c|}{ Tabana yakın borulu isitma sistemi } \\
\hline $\begin{array}{l}\text { Isı enerjisi } \\
\left(\mathbf{k W h} / \mathbf{m}^{2} \text { a) }\right.\end{array}$ & 420,2 & 390,8 & 334,1 & 298,7 & 160,4 & 149,8 & 126,1 & 111,3 & 126,6 & 118,3 & 96,6 & 83,0 \\
\hline $\begin{array}{l}\text { İletim kayıpları } \\
\% 3\end{array}$ & 12,6 & 11,7 & 10,0 & 9,0 & 4,8 & 4,5 & 3,8 & 3,3 & 3,8 & 3,5 & 3,2 & 2,5 \\
\hline $\begin{array}{l}\text { Toplam ISı } \\
\text { enerjisi }\end{array}$ & 432,8 & 402,5 & 344,1 & 307,7 & 165,2 & 154,3 & 129,9 & 114,6 & 130,4 & 123,8 & 99,8 & 85,5 \\
\hline $\begin{array}{l}\text { Domates verimi } \\
\left(\mathrm{kg} / \mathrm{m}^{2}\right)\end{array}$ & \multicolumn{4}{|c|}{50} & \multicolumn{4}{|c|}{34} & \multicolumn{4}{|c|}{32} \\
\hline $\begin{array}{l}\text { Kömürr miktarı } \\
\left(\mathrm{kg} / \mathrm{m}^{2}\right)\end{array}$ & 81,8 & 76,1 & 65,0 & 58,2 & 31,2 & 29,2 & 24,6 & 21,7 & 24,6 & 23,4 & 18,9 & 16,2 \\
\hline $\begin{array}{l}\text { Kömür maliyeti } \\
\left(£ / \mathbf{m}^{2}\right)\end{array}$ & 59,62 & 55,46 & 47,37 & 42,42 & 22,74 & 21,28 & 17,93 & 15,82 & 17,93 & 17,05 & 13,77 & 11,81 \\
\hline $\begin{array}{l}\mathrm{CO}_{2} \text { eşdeğeri } \\
\left(\mathrm{kg} / \mathrm{m}^{2}\right)\end{array}$ & 280,3 & 260,8 & 222,8 & 199,4 & 106,9 & 100,1 & 84,3 & 74,4 & 84,3 & 80,2 & 64,8 & 55,5 \\
\hline $\begin{array}{l}\text { Isıtma maliyeti } \\
\text { (£/kg domates) }\end{array}$ & 1,19 & 1,11 & 0,95 & 0,85 & 0,67 & 0,63 & 0,53 & $\mathbf{0 , 4 7}$ & 0,56 & 0,53 & 0,43 & $\mathbf{0 , 3 7}$ \\
\hline
\end{tabular}




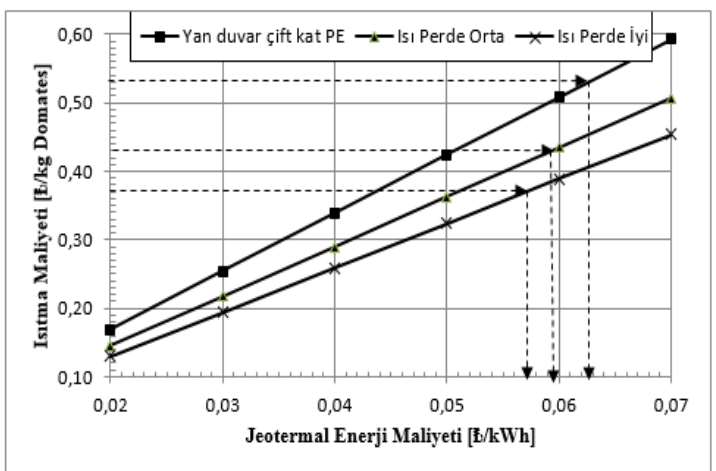

Şekil 2. Kütahya koşullarında farklı donanımlara sahip seralarda birim domates verimi maliyeti için jeotermal enerji birim fiyatı

\section{SONUÇ VE DEĞERLENDİRME}

Türkiye'de seracılık Akdeniz bölgesinde yaygın olarak yapılmaktadır. Ancak son yıllarda Tarım Bakanlığının destek ve teşvikleri ile artan bir şekilde jeotermal kaynakların bulunduğu alanlarda modern seralar kurulmaya başlanmıştır. Türkiye'de jeotermal kaynaklar 1lıman ve karasal iklimin hakim olduğu yerlerde bulunmaktadır. Jeotermal kaynakların yaygın olduğu Kütahya ve Aydın illerinin iklim değerleri incelendiğinde, Aydın ilinin tipik Akdeniz iklimi özelliğini gösterdiği buna karşın Kütahya'nın karasal iklime sahip olduğu görülmektedir.

Seracılığın yoğun olarak yapıldığı Antalya ve zengin jeotermal kaynaklara sahip Aydın'da sıcaklı̆̆ın Haziran ayının ortalarından itibaren $34^{\circ} \mathrm{C}$ 'nin üstüne yükselmesi nedeniyle seralar, Haziran ayının ortalarından Ağustos ayının sonuna kadar boş bırakılmaktadırlar (Çizelge 2). Buna karşın Kütahya ilinde tüm yll üretim yapabilme avantajı ortaya çıkarken 1sıtma için gereksinilen yakıt miktarı Aydın ve Antalya'ya göre oldukça fazladır. Serada sıcaklığın $18 / 16^{\circ} C^{\prime}$ de tutulmak istenmesi durumunda Kütahya ilinde 1sı korumalı serada üretim periyodu boyunca ihtiyaç duyulan 1Sı enerjisi gereksinimi $299 \mathrm{kWh} / \mathrm{m}^{2}$ a olurken, bu değer Aydın'da $111 \mathrm{kWh} / \mathrm{m}^{2} \mathrm{a}$, Antalya'da $83 \mathrm{kWh} / \mathrm{m}^{2}$ a olmaktadır (Çizelge 3). Aydın ve Antalya'da 1S1 enerjisi gereksinimi birbirine yakınken, Kütahya'da ihtiyaç duyulan 1sı enerjisi bu iki ilimize oranla yaklaşık 3 kat daha fazladır.
Kütahya'da serada yapılacak domates üretiminin Antalya ile rekabet edebilmesi için, sera 1sitmasinda kullanılacak jeotermal 1si enerjisinin $\mathrm{kWh}$ bedeli en fazla 0,06 £ olmalıdır (Şekil 2). Jeotermal 1S1 enerjisinin $0,06 \quad € / k W h ’ e$ pazarlanması durumunda, Aydın koşullarında 1s1 perdeli ve yan duvar yalıtımı olan plastik serada yapılacak bir $\mathrm{kg}$ domates üretiminde 1sitma maliyeti $0,20 € / \mathrm{kg}$ olacaktır. Bu da Antalya'ya göre 1sıtma için ödenecek bedelin yaklaşı yarısı anlamına gelmektedir. Bu durum Aydın'da serada yapılacak domates üretiminin Antalya ve Kütahya'ya göre çok karlı olduğunu göstermektedir.

Sera 1sitmasında fosil enerji kaynaklarının kullanılması üretimin karlılığını olumsuz yönde etkilediği gibi, atmosfere verilen $\mathrm{CO}_{2}$ emisyonunu da artırmaktadır. Sera isitmasinda jeotermal enerjinin kullanılması durumunda atmosfere verilecek olan $\mathrm{CO}_{2}$ emisyonu sifira yakındır. Ancak sera 1sitmasında kullanılan jeotermal suyun mutlaka çevreye zarar vermeden reenjeksiyonla kaynağa geri gönderilmesi veya tarım alanlarına zarar vermeden uzaklaştırılması gereklidir. Aksi takdirde verimli tarım alanlarının büyük zarar görmesi söz konusu olacaktır. Sera üreticisinin tek başına kuyu açması ve reenjeksiyonu gerçekleştirmesi ilk yatırım giderleri açısından mümkün değildir. Belirtilen nedenlerle jeotermal alanlarda kurulacak "Organize Seracılık Bölgelerinde" jeotermal kaynakların sera 1sıtması için hazırlanması, günümüz teknolojisine uygun modern sera yapılarının seçilmesi ve enerji korunumu amacıyla teknik önlemlerin alınması koşuluyla, Türkiye'de seracılık sektörüne ve üreticilerine anlamlı katkı sağlanacaktır.

\section{KAYNAKLAR}

1. Baytorun, N.A., Akyüz, A., Üstün, S. 2016. Seralarda Isitma Sistemlerinin Modellemesi ve Karar Verme Aşamasında Bilimsel Verilere Dayalı Uzman Sistemin "ISIGER-SERA" Geliştirilmesi. TÜBİTAK 1140533 nolu proje.

2. Üstün, S., 1993. Çukurova Bölgesinde Farklı Sera İçi İklim Koşullarında Isı Gereksiniminin Hesaplanması Üzerine Bir Araştırma. 
Çukurova Üniversitesi Ziraat Fakültesi. Yüksek Lisans Tezi.

3. Önder, D. 1998. Hatay İli Samandağ İlçesindeki Seraların Yapısal ve Teknik Yönden İncelenmesi ve Yöre Seraları İçin Isı Yükünün Belirlenmesi. Yüksek Lisans Tezi. Ç.Ü.Fen Bilimleri Enstitüsü. Adana

4. Daka, K., Gül, A., Engindeniz, S. 2012. Muğla İlinde Seralarda Dış Satıma Yönelik Domates Üretimi ve Pazarlaması. Ege Üniv. Ziraat Fak. Derg., 2012, 49 (2):175-185

5. Eker, M.M. 2012. Jeotermal Seralarda Hedef, 30 Bin Hektar. Jeotermal Belediyeler Dergisi. Sayı 6. 5-14

6. Tantau, H.J. 1983. Heizungsanlagen im Gartenbau. Verlag Eugen Ulmer. Stuttgart.

7. Zabeltitz, Chr. von. 1986 Gewachshauser. Verlag Eugen Ulmer.

8. IWU 2014. Kumulierter Energieaufwand und CO2-Emisionsfaktoren verschiedener Energietrager und versorgung. www.iwu.de/......./kea.pdf

9. Nisen, A., Grafiadellis, M., Jiménez, R., La Malfa, G., Martinez-Garcia, P.F., Monteiro, A., Verlodt, H., Villele, O., Zabeltitz, C.V., Denis, J.C., Baudoin, W., Garnaud, J.C., 1988. Cultures protegees en climat mediterranean. FAO, Rome.

10.Zabeltitz, C.V. 2011. Integrated Greenhouse Systems for Mild Climates. Climate Conditions, Desing, Construction, Maintenance, Climate Control. SpringerVerlag Berlin Heidelberg. 